\title{
Investigation of speeding and centerline encroachment by motorcycle riders on a 2-lane rural road
}

\author{
PANAGIOTIS LEMONAKIS ${ }^{1}$, GEORGE BOTZORIS ${ }^{2}$, \\ ATHANASIOS GALANIS ${ }^{3}$, NIKOLAOS ELIOU ${ }^{1}$ \\ ${ }^{1}$ Department of Civil Engineering, Section of Transportation, University of Thessaly, \\ Pedion Areos, 38334 Volos, GREECE \\ ${ }^{2}$ Department of Civil Engineering, Section of Transportation, Democritus Thrace University, \\ Kimmeria Campus, 67100 Xanthi, GREECE \\ ${ }^{3}$ Department of Civil Engineering, International Hellenic University, \\ Terma Magnesias, 62124 Serres, GREECE
}

\begin{abstract}
Motorcycle riders are considered as one of the most vulnerable road users group worldwide. This is supported by numerous statistics which reveal that despite the reduction of vehicular fatalities over the last 15 years, the lesser improvement is observed in motorcycle fatal accidents compared to the other road users, either vulnerable or not. Speed and lane departure have been documented as significant contributory factors which precipitate the occurrence of motorcycle accidents. Many researchers attempted to identify and analyze the reasons behind this fact by conducting naturalistic riding studies using instrumented motorcycles and a relatively small number of volunteers. The recent development of multifunctional GPS devices of high positional and speed accuracy has assisted in this direction by allowing the planning of field measurements in a cost and time-effective manner. A similar practice has been adopted to the present study which aims to record and process the recorded data of a mid-scale naturalistic riding study in a two-lane rural road segment in an effort to investigate whether the motorcycle riders follow the posted speed limits. Apart from the investigation of the traveling speed, the high accuracy of the recorded positional data permitted us to compare the trajectory of the riders with the one that is determined by the theoretical model. The latter assumes that the road users travel along the midline of the travel lane and hence the curvature of the horizontal alignment coincides with the actual trajectories. The findings of the paper reveal that the riders do not comply with the posted speed limits to a large extent and follow a trajectory different from the theoretical one. Both findings pose a great risk
\end{abstract}

to motorcycle riders' safety, which strengthening is the main contribution of the present paper.

Key-Words: -Motorcyclists' behavior, Centerline encroachment, Speeding, Rural road, Field measurements, Naturalistic riding study

Received: January 26, 2021. Revised: May 11, 2021. Accepted: May 24, 2021. Published: May 27, 2021.

\section{Introduction}

Motorcyclists are vulnerable road users and account for an important number of road traffic accidents. A report stated that in the USA,5,286 motorcyclists were killed on U.S. roadways in the year 2016, which is an increase $5.1 \%$ comparing to the year 2015 [1]. Furthermore, a report stated that in the EU in the year 2016, motorcyclists were the $22 \%$ of male fatalities and $5 \%$ of female fatalities [2]. In the year 2018, about 25,100 people lost their lives and 135,000 were seriously injured in road accidents in the EU-28 [3]. The target of the EU is the 50\% reduction of road deaths and the $50 \%$ reduction of serious injuries between the years 2020 and 2030 [4].

Risk factors related to the road user are non-use of helmets, alcohol (drinking and driving), speed, rider's age and level of experience, braking errors, drug use, lack of conspicuity, and other risk-taking behavior [5]. Risk factors related to the road environment are mixed traffic, design of road infrastructure, road surface conditions, and roadside hazards [5]. Risk factors related to the vehicle are PTW stability and lack of crash protection. Other risk factors are lack of inclusive urban planning and limited public transport infrastructure [5]. 
A study in Denmark resulted that accident factors in one-third of the investigated accidents and injury factors in about every fourth accident were linked to the road [6]. Speed control is very important in order to decrease traffic accidents. Speeding is the factor that contributes significantly to crashes both in terms of accident severity and frequency of occurrence $[7,8]$.

A study on powered two-wheeler and bicycle accidents in the EU inferred that speed was a factor in the accidents for $22 \%$ of PTW riders. The study concluded that their travel speed was too high for prevailing environmental and traffic conditions. The study noticed that in single-vehicle accidents, 64\% lost control of their motorbike on a curve/bend [9].

Single-motorcycle crashes are overrepresented on horizontal curved road segments. A study by Wang et al., concluded that curve radius is a significant factor which can statistically influence the severity of injuries of single-motorcycle crashes in horizontal curved roadway segments. Speeding is a factor that increases $10.84 \%$ the risk of fatalities in a single-motorcycle crash[10]. Furthermore, a study by Wang et al, noticed that motorcycle crashes are overrepresented on horizontal curves. The crashes were noticed mainly along rural two-lane roads [11].

A study from Xin et al., highlighted the interaction effects between radius and horizontal curve types on the risk of single-motorcycle crashes. The study concluded that an effective countermeasure to decrease motorcycle crashes on curves is speed control, especially on curves with high-speed limit (>50 mph) [12]. Furthermore, this study noticed that in addition to engineering countermeasures, an effective way to improve motorcyclist risk awareness and riding skills in negotiating RTU curves, is a safety education program [12]. A study from Crundall et al., suggested that advanced training can lead to safer riding styles. These riding styles are not acquired by experience alone [13].

Rosey and Auberlet, concluded that lateral position variability indicates an inadequate guidance, incorrect vehicle paths that may increase the likelihood of an accident. Lateral positions variability as an indicator of road design difficulty, allows the identification of problematic sections [14]. Vehicle trajectory analysis can be an advanced tool for road safety [15].

A study from Ray et al., explored ways in order to estimate the trajectories of heavy vehicles in the absence of field-collected data [16]. A study from Abdi et al., analyzed the influence of encroachment angle and median parameters on safety of rural highways using vehicle dynamics performance. This study mentioned that roll-over and skidding are the important factors which affect trucks' cross median crashes. Furthermore, this research resulted that encroachment angle is the most effective parameter for roll-over and skidding [17].

\section{Methodology}

The importance of road geometry to the occurrence of vehicular accidents is documented in many research studies as depicted in the literature review section. The present paper aims to investigate whether the motorcycle riders follow the speed limits of a rural two-lane rural road and follow the path that is determined from the midline of the travel lane, as assumed in various highway design guidelines [18, 19]. For that purpose, a group of 18 motorcycle riders was recruited in order to carry out field measurements under naturalistic riding conditions on a two-lane rural road. The field measurements took place during nighttime and daylight lighting conditions with the use of an instrumented motorcycle and sophisticated equipment (Fig. 1). The use of instrumented vehicles to record operational and behavioral driving data has been extensively used by many researchers.

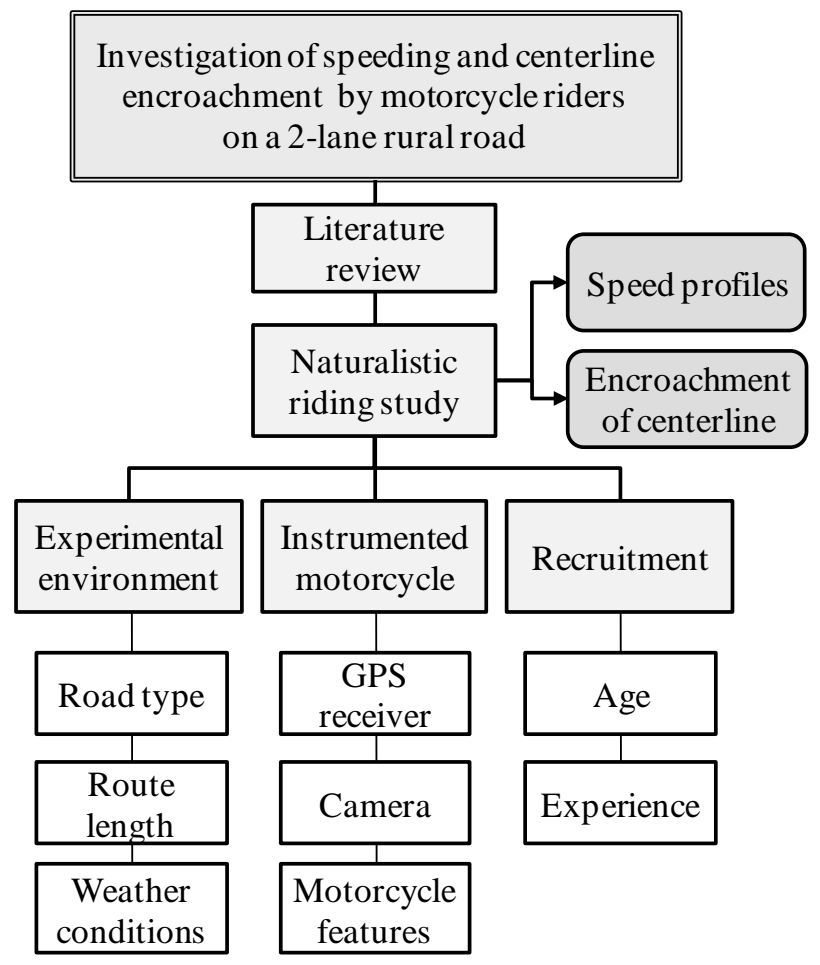

Fig. 1: Methodology followed in the present study

In 2010 Zuriaga et al., collected and processed speed data by implementing a methodology that was based on Global Positioning System. They developed models incorporating the geometric characteristics of the tested road and continuous 
speed data [20]. A case study to estimate the operating speed on a two-lane road segment was the subject of a research study that was conducted by Memon et al. who employed Vbox equipment which is also based on the exploitation of GPS technology to record continuous speed profile data [21]. A few years later Cafiso and Cerni, in an effort to develop continuous speed profile models for two-lane rural roads, carried out naturalistic experiments using GPS devices. The sampling frequency of the equipment was $1 \mathrm{~Hz}$ whilst the measurements took place in approximately $34 \mathrm{~km}$ of rural roads in both directions [22]. The advantages of the GPS systems to record accurate speed profiles and therefore acceleration and deceleration data were exploited by Bella et al., who managed to determine operating speed prediction models by performing 36 driving tests in a two-lane rural road which constituted of 13 tangent-curve configurations. One instrumented vehicle employed providing position data in time intervals of $1 \mathrm{sec}$ with an accuracy of $3 \mathrm{~m}$ [23]. The tangent to curve transition behavior and particularly the speed variation of the vehicles approaching and negotiating a curve was the subject of a research study that was conducted by Pérez-Zuriaga et al. The researchers used continuous speed profile data that were recorded in a $1-\mathrm{Hz}$ GPS device after proper filtering. The measurements lasted for six months under dry weather conditions. Thirty-seven tangent to curve configurations were identified and analyzed from 10 road segments [24].

GPS-based instrumented vehicles were used to collect speed profiles data in another research study that was published in 2014. The naturalistic experiments were carried out with the use of one car for four consecutive months on workdays and under dry weather conditions. The test route was $49.5 \mathrm{~km}$ long and it was consisted of 45 horizontal curves and 46 tangents. The experimental GPS device recorded data with a frequency of $10 \mathrm{~Hz}$ whilst two cameras were also installed to capture the surrounding traffic and environment [25]. The process of the naturalistic driving data that were derived from the use of instrumented vehicles performed in another paper which attempted to correlate the road geometrics with the tracking behavior. A magnetic pedestal on the car-roof permitted the installation of the GPS antenna on a spot with an unobstructed view to the satellites [26]. In a more recent study by Malaghan and Pawar the instrumented vehicle was not a car but heavy vehicles. 15 buses recorded using a GPS device that was operating in $10 \mathrm{~Hz}$ frequency along two lane rural highways of approximately $42 \mathrm{~km}$ length. The researchers analyzed the recorded data in both positional and speed differential terms [27].

The important advantage of the use of instrumented vehicles is that it allows the recording of a dataset throughout long road segments with just one unique piece of equipment. Additionally, since the equipment is not installed within the field of drivers' view it does not affect the natural driving behavior and hence the recorded data are unbiased. On the other hand, radar and pneumatic road tubes enable the collection of multiple data but in a limited number of spots while they affect the driving behavior of the road users once they are perceived. In such a case the road users might change their speed and/or trajectory in order to be consistent with the prevailing traffic conditions. Therefore, the recordings will not reflect the natural behavior of road users. Lastly, the spot recording equipment is insufficient to investigate the differential speed of tangent to curve configurations since they are unable to provide speed profile data throughout a road segment.

\section{Experimental Design}

The field measurements were carried out under good weather and free-flow conditions. The riders travelled along the test route in both directions. The participants consisted of 18 male riders aged between 26 and 63 years old, members of the motorcycle club of the city of Volos and hence, they were all experienced riders and owners of at least one motorcycle with a capacity above $600 \mathrm{cc}$. The riders of the measurements were residents of the city of Volos, a mid-sized Greek city located in central Greece, near to which the experiment took place and consequently they were familiar with the test route (Fig. 2). A toolbox talk took place before the experiments in which the riders were informed about the exact route they had to follow (starting and ending point and return) but not about the purposes of the measurements.

The instrumented vehicle used in the field measurements was manufactured in 2007. It is a vehicle widely spread in Greek roads since it combines comfort and performance on pavements with different characteristics and copes sufficiently with the poor maintained rural roads. The riders who were not familiar with the specific vehicle had the opportunity to perform test rides before the execution of the measurements for as long as they needed.

The experimental route was a 2-lane rural highway of approximately $7.6 \mathrm{~km}$ length and consisted of 21 horizontal curves from which 11 left-handed (LH) and 10 right-handed (RH) and 21 
tangents. The radii of the horizontal curves ranged between $195 \mathrm{~m}$ and $900 \mathrm{~m}$ whilst the length of the tangents ranged between $10 \mathrm{~m}$ and $424 \mathrm{~m}$. The pavement of each direction consisted of a travel lane of $3.75 \mathrm{~m}$ width and a shoulder of $1.5 \mathrm{~m}$ width and therefore, the total width of the road's cross-section was $10.5 \mathrm{~m}$. The characteristics of the test route are presented in Table 1.

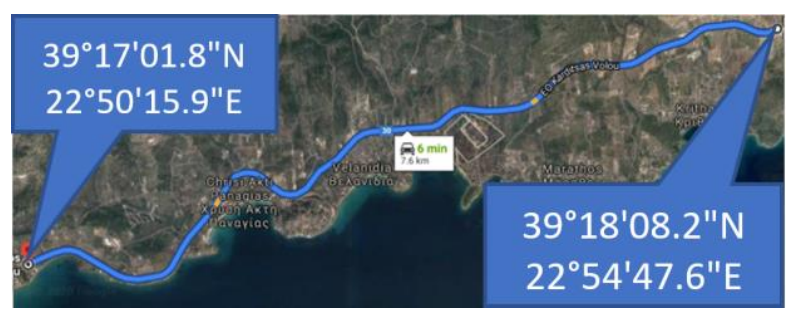

Fig. 2: The experimental route

Table 1: Characteristics of the experimental route Volos - Anchialos

\begin{tabular}{lrlr}
\hline Curve & $\mathrm{R}_{\text {curve }}$ & Direction* & $\begin{array}{r}\text { Preceding } \\
\text { tangent }\end{array}$ \\
\hline K1 & 900 & LH curve & 300 \\
\hline K2 & 250 & LH curve & 61 \\
\hline K3 & 330 & RH curve & 308 \\
\hline K4 & 200 & RH curve & 66 \\
\hline K5 & 900 & RH curve & 31 \\
\hline K6 & 800 & LH curve & 169 \\
\hline K7 & 200 & RH curve & 76 \\
\hline K8 & 195 & LH curve & 98 \\
\hline K10 & 225 & RH curve & 48 \\
\hline K11 & 380 & LH curve & 10 \\
\hline K12 & 270 & RH curve & 44 \\
\hline K13 & 220 & LH curve & 424 \\
\hline K14 & 200 & RH curve & 22 \\
\hline K15 & 300 & LH curve & 18 \\
\hline K16 & 400 & LH curve & 131 \\
\hline K17 & 300 & LH curve & 140 \\
\hline K18 & 300 & RH curve & 214 \\
\hline K19 & 220 & LH curve & 100 \\
\hline K20 & 220 & RH curve & 119 \\
\hline K21 & 250 & RH curve & 125 \\
\hline min & 195 & & 10 \\
\hline max & 900 & & 424 \\
\hline Std. dev. & 229.84 & & 109.24 \\
\hline$*$ & LH for left-handed curves \\
& RH for right-handed curves & \\
\hline & & & \\
\hline & & \\
\hline
\end{tabular}

As mentioned in section 2, the measurements were carried out during nighttime and daytime lighting conditions. The daytime measurements took place on the $22^{\text {nd }}$ of September 2019 whereas the nighttime measurements a week later.

Lastly, a GPS receiver (Stonex S9 III) and an HD camera employed to record and filter the recordings. The former was installed at the tale of the motorcycle while the latter above the headlamps (Fig. 3).

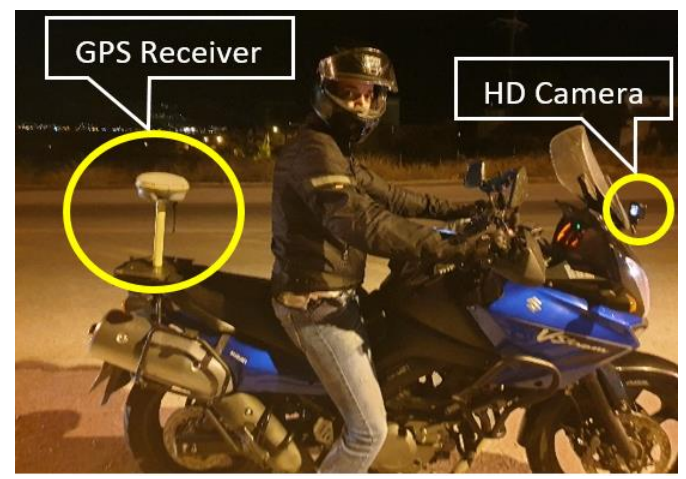

Fig. 3: Instrumented motorcycle

\section{Results}

The raw data as they were recorded by the GPS device are presented in Figures 3 and 4 which depict the speed profiles of the riders based on the different lighting conditions. The recordings from the GPS receiver were filtered in order to process only data which correspond to free-flow conditions. That was accomplished with the use of the HD camera. However due to low traffic conditions only a small number of data excluded from the final dataset. Moreover, instantaneous GPS signal loss (GSL) led to the recording of noise data. These data were also excluded from the analysis. Typical examples of noisy data are also illustrated in Figures 4 and 5.

In these examples a horizontal line represents the general posted speed limit along the test route. That limit was $70 \mathrm{~km} / \mathrm{h}$ except from local speed limits before and after the junctions where the speed limit was reduced to $50 \mathrm{~km} / \mathrm{h}$. Apparently, any data above this line denotes that the speed limit was breached while any data below this line denotes that the riders comply with the speed limits.

Table 2 presents the total path length of each measurement along the test route in both directions, and the total centerline encroachment length. As mentioned before due to GSL for a short period few measurements had noisy data which affect the total path length. These measurements are shaded grey in Table 2 and were excluded from the post-process of the measurements. 


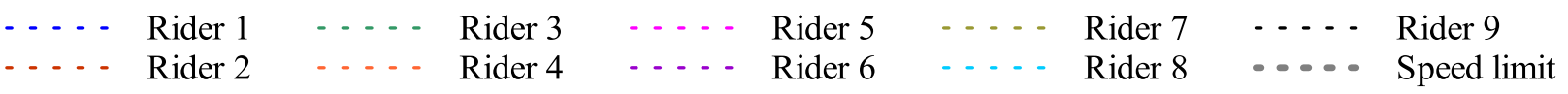


Fig. 4: Speed profiles of the riders for Volos-Anchialos route during daylight and nighttime


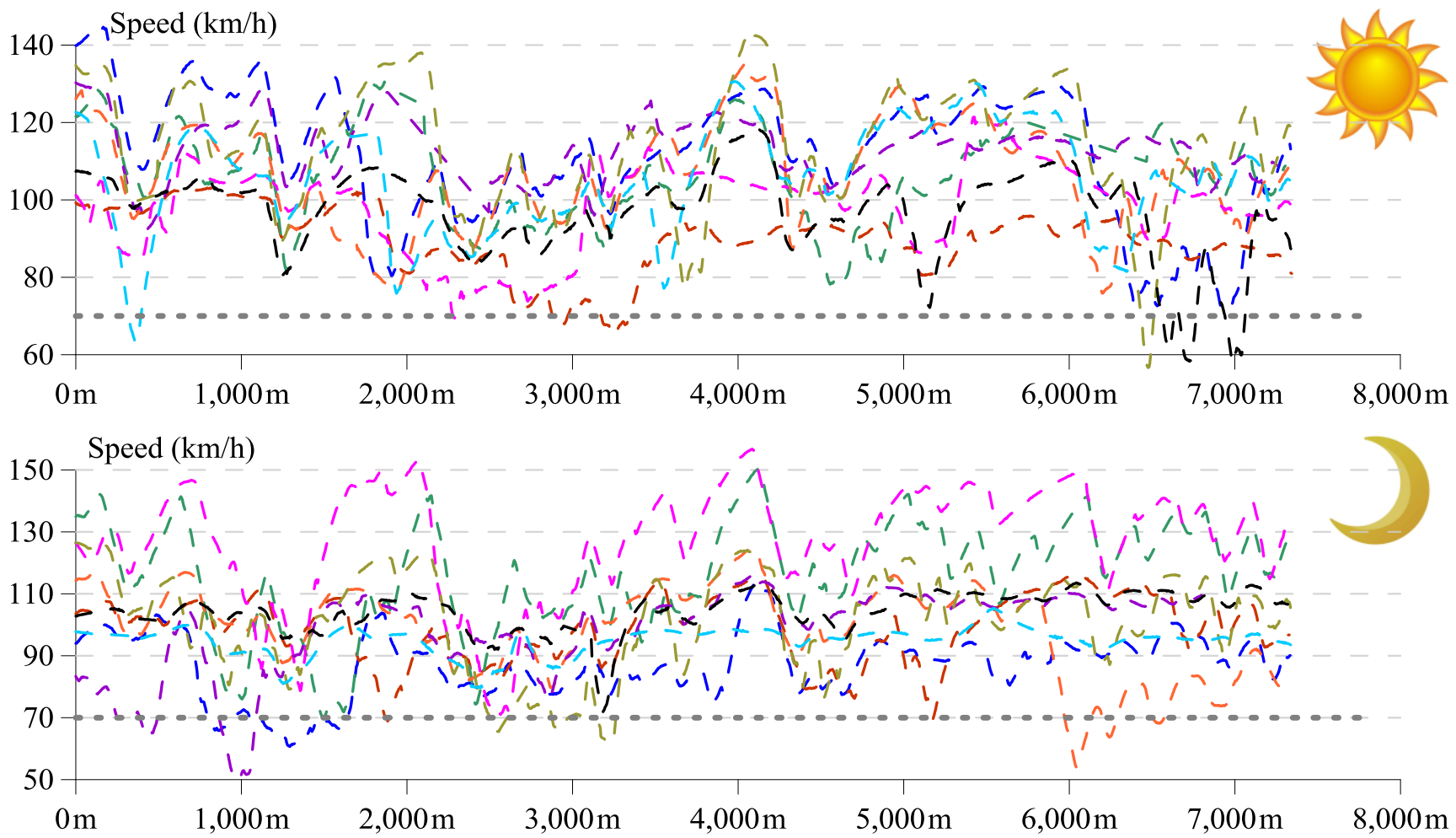

Fig. 5: Speed profiles of the riders for Anchialos-Volos route during daylight and nighttime 
Table 2: Path and encroachment of centerline lengths

\begin{tabular}{|c|c|c|c|c|c|c|c|c|c|c|c|}
\hline \multirow{3}{*}{ 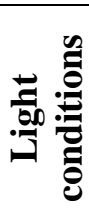 } & \multirow{3}{*}{ 离 } & \multicolumn{5}{|c|}{ Volos-Anchialos route } & \multicolumn{5}{|c|}{ Anchialos-Volos route } \\
\hline & & \multirow{2}{*}{$\begin{array}{c}\text { Path } \\
\text { length } \\
\text { (m) }\end{array}$} & \multicolumn{2}{|c|}{$\begin{array}{l}\text { Encroachment } \\
\text { of centerline }\end{array}$} & \multicolumn{2}{|c|}{$\begin{array}{l}\text { Speed } \\
(\mathbf{k m} / \mathbf{h})\end{array}$} & \multirow{2}{*}{$\begin{array}{c}\text { Path } \\
\text { length } \\
\text { (m) }\end{array}$} & \multicolumn{2}{|c|}{$\begin{array}{c}\text { Encroachment } \\
\text { of centerline }\end{array}$} & \multicolumn{2}{|c|}{$\begin{array}{l}\text { Speed } \\
(\mathbf{k m} / \mathbf{h})\end{array}$} \\
\hline & & & $\begin{array}{l}\text { Length } \\
\text { (m) }\end{array}$ & Percentage & Mean & Std. dev. & & $\begin{array}{l}\text { Length } \\
\text { (m) }\end{array}$ & Percentage & Mean & Std. dev. \\
\hline \multirow{10}{*}{ 㿣 } & 1 & 7,338 & 204 & $2.8 \%$ & 107.9 & 9.2 & 7,337 & 368 & $5.0 \%$ & 108.9 & 17.6 \\
\hline & 2 & 7,321 & 13 & $0.2 \%$ & 93.9 & 7.0 & 7,344 & 253 & $3.5 \%$ & 88.9 & 8.8 \\
\hline & 3 & 7,337 & 190 & $2.6 \%$ & 99.2 & 11.4 & 7,305 & 339 & $4.6 \%$ & 104.2 & 11.9 \\
\hline & 4 & 7,338 & 0 & $0.0 \%$ & 100.6 & 16.5 & 7,341 & 490 & $6.7 \%$ & 104.7 & 13.4 \\
\hline & 5 & 7,331 & 128 & $1.8 \%$ & 92.3 & 11.8 & 7,341 & 329 & $4.5 \%$ & 97.2 & 11.4 \\
\hline & 6 & 7,304 & 95 & $1.3 \%$ & 98.2 & 16.7 & 7,257 & 351 & $4.8 \%$ & 112.7 & 10.5 \\
\hline & 7 & 7,336 & 0 & $0.0 \%$ & 109.4 & 16.0 & 7,334 & 182 & $2.5 \%$ & 111.5 & 16.6 \\
\hline & 8 & 7,339 & 0 & $0.0 \%$ & 107.4 & 13.4 & 7,332 & 0 & $0.0 \%$ & 103.6 & 14.2 \\
\hline & 9 & 7,350 & 0 & $0.0 \%$ & 92.6 & 12.3 & 7,346 & 313 & $4.3 \%$ & 95.1 & 12.4 \\
\hline & \multicolumn{2}{|c|}{ Sum } & 630 & & & & & 2,625 & & & \\
\hline \multirow{10}{*}{ 节 } & 1 & 7,340 & 71 & $1.0 \%$ & 80.7 & 5.6 & 7,334 & 0 & $0.0 \%$ & 85.5 & 10.6 \\
\hline & 2 & 7,241 & 97 & $1.3 \%$ & 96.8 & 11.8 & 7,329 & 179 & $2.4 \%$ & 97.8 & 10.9 \\
\hline & 3 & 7,337 & 125 & $1.7 \%$ & 124.5 & 14.6 & 7,330 & 118 & $1.6 \%$ & 117.4 & 14.3 \\
\hline & 4 & 7,347 & 0 & $0.0 \%$ & 97.4 & 5.9 & 7,338 & 48 & $0.7 \%$ & 95.8 & 15.0 \\
\hline & 5 & 7,314 & 126 & $1.7 \%$ & 121.0 & 11.6 & 7,334 & 96 & $1.3 \%$ & 124.0 & 19.7 \\
\hline & 6 & 7,338 & 95 & $1.3 \%$ & 94.0 & 14.0 & 7.227 & 198 & $2.9 \%$ & 96.6 & 14.3 \\
\hline & 7 & \begin{tabular}{|l|l|}
7,337 \\
\end{tabular} & 43 & $0.6 \%$ & 98.7 & 11.7 & 7,336 & 64 & $0.9 \%$ & 99.5 & 16.0 \\
\hline & 8 & 7,335 & 0 & $0.0 \%$ & 102.2 & 5.5 & 7,337 & 34 & $0.5 \%$ & 108.7 & 4.6 \\
\hline & 9 & 7,332 & 0 & $0.0 \%$ & 103.9 & 3.6 & 7,327 & 19 & $0.3 \%$ & 104.1 & 6.7 \\
\hline & \multicolumn{2}{|c|}{ Sum } & 557 & & & & & 756 & & & \\
\hline
\end{tabular}

\section{Conclusions and recommendations for future research}

As illustrated in Figures 4 and 5, the riders do not follow the posted speed limit of the test route in both directions and regardless of the lighting status, to a great extent. That is particularly hazardous especially during the nighttime measurements due to the reduced field of view that is perceived by the riders.

According to Table 2, the riders encroach the centerline of the road on a percentage of $0 \%$ to $6.67 \%$ of the travel path. Therefore, they spend a substantial amount of time traveling in the opposite direction lane. However, in-depth analysis on this phenomenon is recommended in order to identify the circumstances under which riders invade in the opposite direction and whether that is acceptable under certain conditions or not e.g., avoidance of obstacle on the pavement, presence of stray animals on the right shoulder.

The riders do not strictly follow the geometry of the road and hence the assumption that the road users' trajectory coincides with that of the centerline of the travel lane is unrealistic. That is concluded by comparing the different lengths of the travel paths for each measurement (Table 2). Moreover the following conclusions are also drawn:

- The theoretical path length (according to the horizontal alignment of the road) is greater than the actualized path that was traversed by the riders. The mean reduction of the daytime measurements for the route Volos-Anchialos is $0.13 \%$ and for the opposite direction $0.21 \%$. The mean reductions of the nighttime measurements are $0.24 \%$ and $0.28 \%$ respectively.

- In total the riders reduce the theoretical path by $0.17 \%$ during daytime and by $0.26 \%$ during nighttime. Therefore the riders cut the curves more frequently during nighttime lighting conditions. A rational explanation of this finding is the fact that during night the drivers are able to perceive earlier the presence of a vehicle that is traveling at the opposite direction.

- A comparison between the mean speeds for the two directions reveals that riders tend to travel faster at the backwards measurements. Specifically there is an increase in the mean 
speed between the two directions from 100.2 $\mathrm{km} / \mathrm{h}$ to $103.0 \mathrm{~km} / \mathrm{h}$ and from $102.1 \mathrm{~km} / \mathrm{h}$ to $103.3 \mathrm{~km} / \mathrm{h}$ for the daytime and the nighttime measurements respectively. That is an indication that the familiarity with a road segment is associated with higher speeds.

- The riders travel faster during the nighttime measurements. That is also rational since at night the riders cut the curves more frequently and hence they can speed more.

Although the results of the present study are originated from a mid-scale naturalistic riding study, particular concerns are raised since the majority of the motorcycle riders encroach the centerline of the test route to a substantial extent. That poses a great risk to the safety of the riders themselves as well as to the safety of the other road users traveling in the opposite direction. The risk is even greater given that the riders' trajectories, especially along the horizontal curves do not meet the theoretical assumption that the road users follow the centerline of the traffic lane. In segments where the curvature of the real trajectory is greater that the geometric one, the friction demands are increased and hence the stability of the motorcycle deteriorates. However along tangents that risk is vanished since the centrifugal acceleration is missing. Further measurements are highly recommended including other vehicle types aiming at the evaluation of the present findings.

\section{References:}

[1] Motorcyclist Traffic Fatalities by State 2017 Preliminary Data, Spotlighton Highway Safety, Governors Highway Safety Association, 2018.

[2] European Commission, Traffic Safety Basic Facts on Main Figures, European Commission, Directorate General for Transport, June 2018.

[3] European Commission, Road safety: Data show improvements in 2018 but further concrete and swift actions are needed, Brussels, 4 April 2019.

[4] European Commission, EU Road Safety Policy Framework 2021-2030 - Next steps towards "Vision Zero", Brussels, 19.6.2019, SWD (2019) 283 final.

[5] Powered two- and three-wheeler safety: a road safety manual for decision-makers and Practitioners, World Health Organization, 2017.

[6] Danish Road Traffic Accident Investigation Board. Why do road traffic accidents happen? December 2014.
[7] Mohan, D., Tiwari, G., Khayesi, M., and Nafukho, F.M., Road traffic injury prevention: training manual, World Health Organization, 2006.

[8] UK Parliament, House of Commons, Transport, Local Government and the Regions - Ninth Report, The consequences of speed, Transport, Local Government and the Regions Committee Publications, Session 2001-02, 2002.

[9] Morris, A.P., Brown, L.A., Thomas, P., Davidse, R.J., Phan, V., Margaritis, D., Usami, D., Robibaro, M., Krupińska, A., Sicińska, K., Ziakopoulos, A., Theofilatos, A., and Yannis, G. 2018. Safer Wheels study on powered twowheeler and bicycle accidents in the EU - Final report. Luxembourg: Publications Office of the European Union.

[10] Wang, Z., Lee, C., and Lin, P-S., Modeling injury severity of single-motorcycle crashes on curved roadway segments, Transportation Research Board 93rd Annual Meeting, Washington D.C., 2014.

[11] Wang, Z., Lee, C., Lin, P-S., Guo, R., Xin, C., Kolla, R.D.T.N., Yang, R., and Vasili, A., Study on Motorcycle Safety in Negotiation with Horizontal Curves in Florida and Development of Crash Modification Factors, Florida Department of Transportation, USF Center for Urban Transportation Research, October 2018.

[12] Xin, C., Wang, Z., Lee, C., Lin, P, Chen, T., Guo, R, and Lu, Q., Development of crash modification factors of horizontal curve design features for single-motorcycle crashes on rural two-lane highways: A matched case-control study, Accident Analysis \& Prevention, 123, 2019, pp. 51-59.

[13] Crundall, E., Stedmon, A.W., Saikayasit, R., and Crundall, D., A simulator study investigating how motorcyclists approach sideroad hazards, Accident Analysis and Prevention, 51, 2013, pp. 42-50.

[14] Rosey, F., and Auberlet, J-M., Trajectory variability: Road geometry difficulty indicator, Safety Science, 50, 2012, pp. 1818-1828.

[15] Jacob, B., and Violette, E., Vehicle trajectory analysis: an advanced tool for road safety, Procedia - Social and Behavioral Sciences, 48, 2012, pp. 1805-1814.

[16] Ray, M.H., Carrigan, C.E., and Plaxico, C.A., Heavy Vehicle Encroachment Trajectories, First International Roadside Safety Conference, 2017.

[17] Abdi, A., Nassimi, O., Salehfard, R., and Moghaddam, V.N., Analysing the Influence of Encroachment Angle and Median Parameters 
on Safety of Rural Highways Using Vehicle Dynamics Performance, IOP Conference Series: Materials Science and Engineering, 471(6), 2019.

[18] Lamm, R., Psarianos, B., and Mailaender, T., Highway Design and Traffic Safety Engineering Handbook, McGraw-Hill, 1999.

[19] Road Design Guidelines Manual, NAMA, Ministry for the Environment, Physical Planning and Public Works, 2001 (in Greek).

[20] Zuriaga AMP, García AG, Torregrosa FJC, and D'Attoma P. Modeling Operating Speed and Deceleration on Two-Lane Rural Roads with Global Positioning System Data, Transportation Research Record, 2171(1), 2010, pp. 11-20.

[21] Memon, R.A., Khaskheli, G.B., and Dahani, M.A., Estimation of operating speed on twolane two-way roads along N-65 (SIBI-Quetta), International Journal of Civil Engineering, 10 (1), 2012, pp. 25-31.

[22] Cafiso, S., and Cerni, G., New Approach to Defining Continuous Speed Profile Models for Two-Lane Rural Roads, Transportation Research Record, 2309(1), 2012, pp. 157-167.

[23] Bella, F., Calvi, A., and D'Amico, F., Operating Speed Prediction for Italian TwoLane Rural Roads Using Speed Profiles from GPS Data, 4th International Conference on Road Safety and Simulation RSS 2013, 23-25 October 2013, Rome, Italy.

[24] Pérez-Zuriaga, A.M., Camacho-Torregrosa, F.J., and García, A., Tangent-to-Curve Transition on Two-Lane Rural Roads Based on Continuous Speed Profiles, Journal of Transportation Engineering, 139(11), 2013, pp. 1048-1057.

[25] Montella, A., Pariota, L., Galante, F., Imbriani, L.L., and Mauriello, F., Prediction of Drivers' Speed Behavior on Rural Motorways Based on an Instrumented Vehicle Study, Transportation Research Record, 2434, 2014, pp. 52-62.

[26] Cerni, G., and Bassani, M., Naturalistic driving data collection to investigate into the effects of road geometrics on track behaviour, Transportation Research Part C: Emerging Technologies, 77, 2017, pp. 1-15.

[27] Malaghan, V., and Pawar, D.S., Operating Speed Differential Model for Heavy Vehicles using GPS Driving Data, Transportation Research Procedia, 48, 2020, pp. 3706-3716.

\section{Contribution of individual authors to the creation of a scientific article (ghost writing policy)}

Panagiotis Lemonakis contributed to all steps of the present study and particularly he organized, executed and, analyzed the field measurements.

George Botzoris was responsible for the set-up of the field measurements and the post-statistical analysis.

Athanasios Galanis contributed to the literature review of the study and the post-statistical analysis.

Nikolaos Eliou assisted in the recruitment and execution of the field measurements presented in section 3 .

\section{Sources of funding for research presented in a scientific article or scientific article itself}

This research study was conducted under the postdoc scholarship supported by the University of Thessaly and exclusively funded by Stavros Niarchos Foundation.

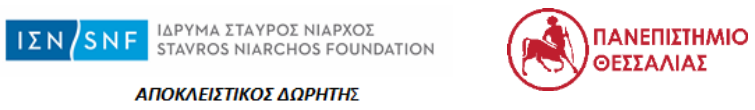

\section{Creative Commons Attribution}

\section{License 4.0(Attribution 4.0 \\ International, CC BY 4.0)}

This article is published under the terms of the Creative Commons Attribution License 4.0 https://creativecommons.org/licenses/by/4.0/deed.en US 